\title{
Analysis of day rainfall characteristics of Zhengzhou
}

\author{
Zhenzhou SHEN, Wenyi YAO ${ }^{*}$, Peiqing XIAO, and Xueqin YANG
}

Key Laboratory of Soil and Water Loss Process and Control on the Loess Plateau of the MWR, Yellow River Institute of Hydraulic Research, Zhengzhou, 450003, Henan

\begin{abstract}
Raindrop characteristics, including speed and size of raindrops, in Zhengzhou city of Yellow River basin were analyzed through a natural rainfall on the loess slope. Results showed that the process of natural rainfall belonged to a parabola and counts, size and terminal velocity would increase with the rainfall intensity rising. Besides, the size and terminal velocity of natural raindrops were relatively scattered; In the process of individual rainfall, the terminal velocity and its peak value were mainly focused between $0.8 \sim 5 \mathrm{~m} / \mathrm{s}$ and $1 \mathrm{~m} / \mathrm{s}$, respectively. Size of raindrops were mainly consisted of $0.125-0.5 \mathrm{~mm}$, among which the terminal velocity of raindrops with a size of $0.125 \mathrm{~mm}, 0.25 \mathrm{~mm}, 0.375 \mathrm{~mm}, 0.5 \mathrm{~mm}$ were primarily 0.8 $3.4 \mathrm{~m} / \mathrm{s}, 0.6-3.4 \mathrm{~m} / \mathrm{s}, 0.8-1 \mathrm{~m} / \mathrm{s}, 1-1.4 \mathrm{~m} / \mathrm{s}$, respectively.
\end{abstract}

\section{Introduction}

Loess Plateau, the region with extremely serious problems of loss of water and soils in the world, has been the main source of outflow sediments in Yellow River. Management of the sediments is the critical factor to curb sediment hazard ${ }^{[1-2]}$. However, due to complexity of soil and water loss and limitations in observation methods and procedures ${ }^{[3]}$ for field research.For example, mechanism of watershed soil and water loss, erosion and sediment yieldis still unknown., There are still lack of practical soil and water loss models for Loess Plateau ${ }^{[4]}$, around the world ${ }^{[4-8]}$. These restrictions limit the comprehensive development of soil and water loss management ${ }^{[9-10]}$.

Study of natural rainfall distribution [11] by combining the field observation and laboratory test are the focus of research to explore the mechanism of soil and water loss to develop the optimized model and to establish a mathematical model of soil and water loss on the Loess PlateauTherefore it is imperative to analyze the scale transformation and rainfall similarity and finally the raindrops characteristics in the soil erosion experiments must be solved ${ }^{[12-15]}$. This study aims to analyze the terminal velocity and gradation (sizes) of raindrops, combined with the eroded sediments resulted from different rainfall conditions in order to offer a technology support for dynamic rainfall simulation.

\section{Experimental program}

\subsection{Experiment design of runoff plots}

The experiment was carried out at the Zhengzhou test base of model Yellow River(3445'36"N 11340'27"E) of Yellow River Institute of Hydraulic Research. The length, width, depth and slope of runoff plots are $5.0 \mathrm{~m}$, $1.0 \mathrm{~m}, 0.6$ mand $20^{\circ}$, respectively. Structure of plots is brick-concrete and a water channel is at the outlet in each plots. Soil filled in each plots is surface loessal soil from the Mangshan Mountain in Zhengzhou, with the proportion of particle size of 0.05-0.01 mm, 0.02-0.05 $\mathrm{mm}$ being $43.4 \%$ and $35.45 \%$, respectively. Soil bulk density is $1.20 \mathrm{~g} / \mathrm{cm}^{3}$.

\subsection{Test methods}

The $5 \mathrm{~m}$ long slope was divided into five fractural surface from top to bottom. The laser optical disdrometer was used here to collect the information about characteristics of raindrops, including intensity, size, terminal velocity and number under the same terminal velocity. Slope velocity radar gun and steel rule were used to record hydraulics parameters, including speed, width and depth of runoff. Sediments were collected by 1 minute after producing runoff and analyzed the parameters mentioned above. Erosion amounts and sediment concentration were calculated by the method of substitution or oven drying and calculated the parameters like infiltration of runoff according to rainfall and runoff yield.

\footnotetext{
* Corresponding author: 15981989220@139.corn
} 

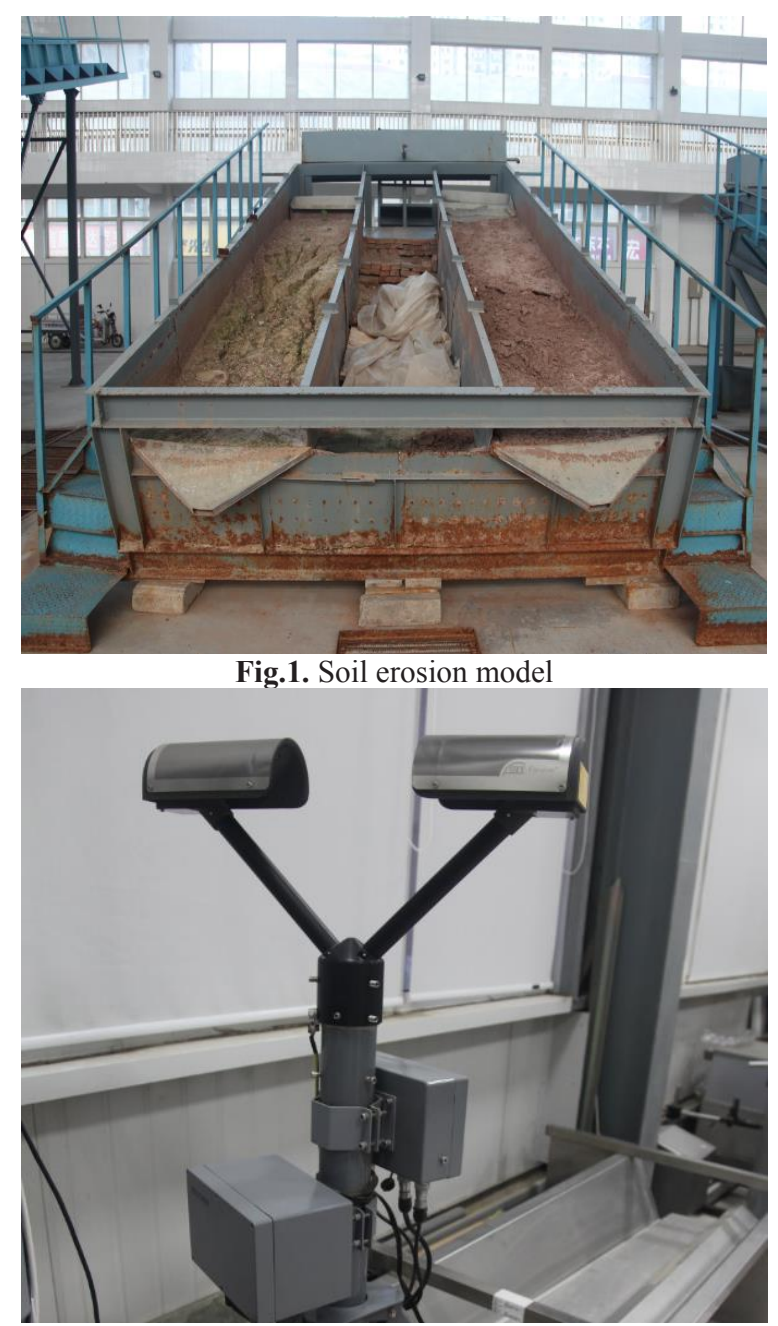

Fig.2. The laser optical disdrometer

\section{Results and discussion}

In this paper, five typical rainfall time points in natural rainfall on April 23, 2016 (hereinafter referred to as 20160423) were selected. The length of each time point was $1 \mathrm{~min}$. The particle size of raindrops in the min length, the speed of raindrops, and the number of raindrops with the same raindrops were collected by LPM laser raindrop spectrometer. The raindrops characteristics were also analyzed. The results are as follows.

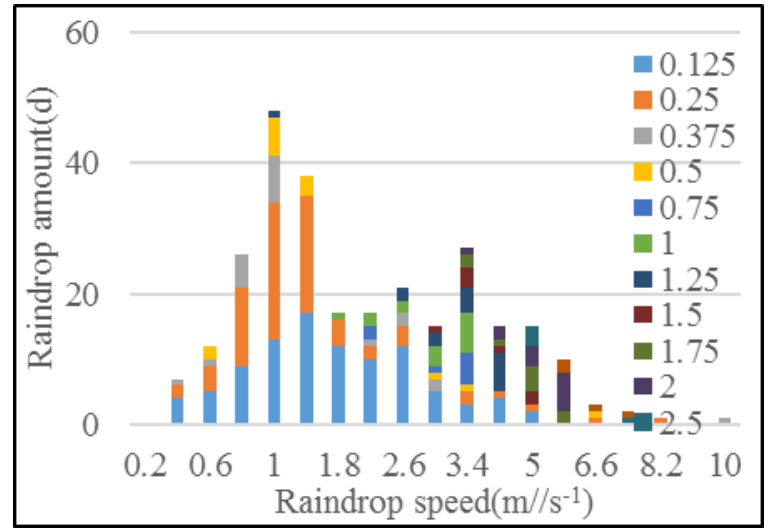

Fig.3. the first minute during the natural rainfall on 20160423
The distribution of the particle size and the final velocity of the raindrops in the first 1 minute during the natural rainfall on 20160423 is shown in Fig.3. It can be seen from the figure that the final velocity of the raindrops in the first $1 \mathrm{~min}$ of the rainfall is mainly concentrated between $0.4-5.8 \mathrm{~m} / \mathrm{s}$ and the peak velocity is $1 \mathrm{~m} / \mathrm{s}$, and the number of raindrops with the final velocity of the raindrop is about 48 , accounting for about $17 \%$; The rainfall is mainly composed of raindrops with particle size of $0.125-0.5 \mathrm{~mm}$. The final velocity of $0.125 \mathrm{~mm}$ is mainly between $0.4-4.2 \mathrm{~m} / \mathrm{s}$, and the final velocity of the raindrops with $0.25 \mathrm{~mm}$ particle size is mainly concentrated on the range of $0.4-3.4 \mathrm{~m} / \mathrm{s}$, $0.375 \mathrm{~mm}$ diameter of the raindrops mainly concentrated on the $0.8-1 \mathrm{~m} / \mathrm{s}$, the $0.5 \mathrm{~mm}$ diameter of the raindrops mainly concentrated on the $1-1.4 \mathrm{~m} / \mathrm{s}$.

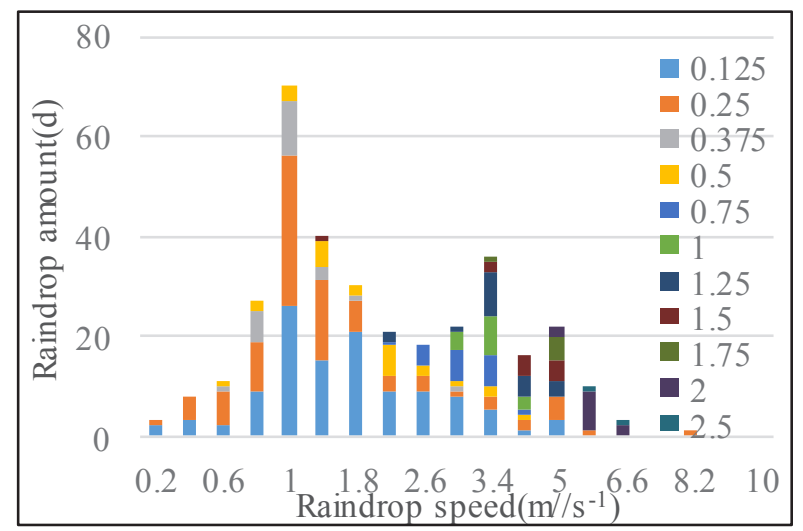

Fig.4 the second min during the natural rainfall on 20160423

According to the distribution of the raindrops and the final velocity of the raindrops in the second minute during the natural rainfall process (Figure 4), the final velocity of the raindrops in the second minute of the rainfall is mainly concentrated between $0.4-5.8 \mathrm{~m} / \mathrm{s}$ and the peak velocity is $1 \mathrm{~m} / \mathrm{s}$, with the number of raindrops at the end of the raindrops is about 70 , accounting for about $15 \%$; We can also see the rainfall is mainly composed of $0.125-0.5 \mathrm{~mm}$ diameter raindrops, the final velocity of $0.125 \mathrm{~mm}$ particle size is mainly concentrated on the $0.8-3.4 \mathrm{~m} / \mathrm{s}$, the final velocity of $0.25 \mathrm{~mm}$ size is mainly concentrated in the $0.4-5 \mathrm{~m} / \mathrm{s}$, the final velocity of $0.375 \mathrm{mmparticle}$ size is mainly concentrated in the 0.8 $1.4 \mathrm{~m} / \mathrm{s}$, the final velocity of $0.5 \mathrm{~mm}$ particle size is mainly concentrated in the $1-2.6 \mathrm{~m} / \mathrm{s}$.

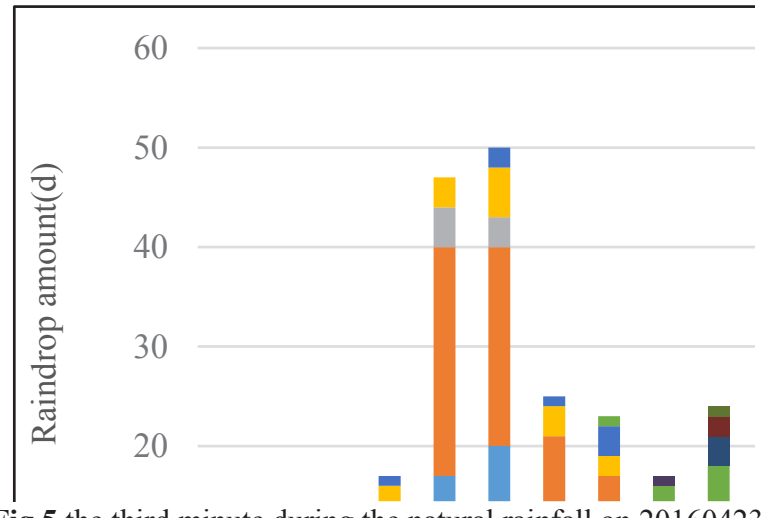

Fig.5 the third minute during the natural rainfall on 20160423

Fig. 5 shows the distribution of the particle size and the final velocity of the raindrops in the third minute 
during the natural rainfall in 20160423, it can be seen from the figure that the final velocity of the rains in the third minute of the rainfall is mainly concentrated in the range of $0.4-6.6 \mathrm{~m} / \mathrm{s}$, and the velocity of the raindrops in the third minute of the natural rainfall is analyzed. At the same time, the final velocity and the peak velocity was formed, the value is $1.4 \mathrm{~m} / \mathrm{s}$ and $3.4 \mathrm{~m} / \mathrm{s}$ respectively. That is, most of the raindrop speed is $1.4 \mathrm{~m} / \mathrm{s}$ and $3.4 \mathrm{~m} / \mathrm{s}$ or so, with the number of raindrops about 50 and 28 or so, accounting for about $30 \%$ or so; We can also see the rainfall is mainly composed of $0.125-1 \mathrm{~mm}$ diameter raindrops, of which $0.125 \mathrm{~mm}$ particle size of the end of the rain mainly concentrated in the $0.4-3.4 \mathrm{~m} / \mathrm{s}, 0.25 \mathrm{~mm}$ diameter of the raindrops mainly concentrated in the 0.6$4.2 \mathrm{~m} / \mathrm{s}$, the $0.375 \mathrm{~mm}$ diameter of the raindrops mainly concentrated in the $0.6-1.4 \mathrm{~m} / \mathrm{s}$, the $0.5 \mathrm{~mm}$ diameter raindrops is mainly between $0.8-2.2 \mathrm{~m} / \mathrm{s}$, the $0.75 \mathrm{~mm}$ particle size of the raindrops mainly concentrated in the $1.4-2.6 \mathrm{~m} / \mathrm{s}$, the $1 \mathrm{~mm}$ particle size of the rain speed is mainly between $2.6-3.4 \mathrm{~m} / \mathrm{s}$.

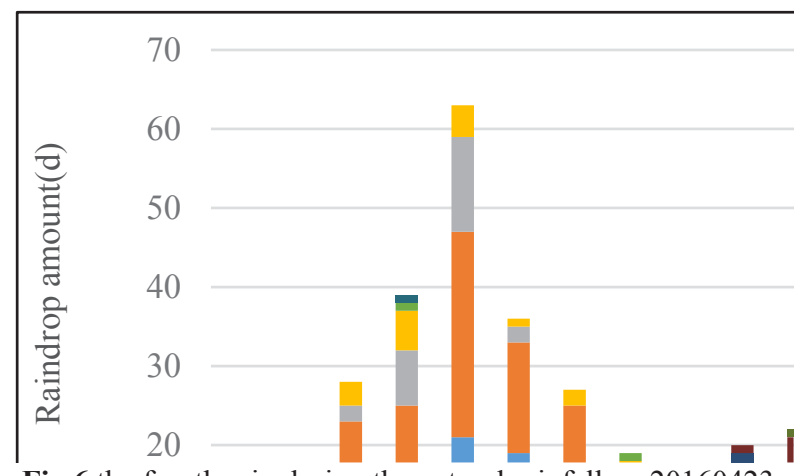

Fig.6 the fourth min during the natural rainfall on 20160423

Fig. 6 shows the distribution of the particle size and the final velocity of the raindrops in the fourth minute during the natural rainfall in 20160423. It can be seen that final velocity of the raindrops in the fourth minute of the rainfall is mainly concentrated between $0.4-5 \mathrm{~m} / \mathrm{s}$, forming two final velocity peaks, namely $1 \mathrm{~m} / \mathrm{s}$ and $4.2 \mathrm{~m} / \mathrm{s}$ respectively, that is, most of the raindrops is mainly $1 \mathrm{~m} / \mathrm{s}$ and $4.2 \mathrm{~m} / \mathrm{s}$ or so, with the number of raindrops is 63 and 30 or so, accounting for about $30 \%$; We can also see the particle size of rainfall is mainly $0.125-0.5 \mathrm{~mm}$ raindrops. Of which $0.125,0.25,0.375$, $0.5 \mathrm{~mm}$ particle size of the rain speed is mainly concentrated in $0.4-3.4,0.4-4.2,0.8-1,0.6-2.6 \mathrm{~m} / \mathrm{s}$.

Fig. 7 shows the distribution of the particle size and the final velocity of the raindrops in the 5 th minute during the natural rainfall, we can see that the final velocity of the raindrops in the first $5 \mathrm{~min}$ of the rainfall is mainly concentrated between $0.4-6.6 \mathrm{~m} / \mathrm{s}$, and the velocity of the raindrops in the 5th minute during the natural rainfall is analyzed. Forming a final velocity peak is $1 \mathrm{~m} / \mathrm{s}$, that is, most of the raindrop speed is $1 \mathrm{~m} / \mathrm{s}$, with the raindrop speed of the number of raindrops for about 54 , accounting for about $17 \%$; We can also see the rainfall is mainly composed of $0.125-0.5 \mathrm{~mm}$ diameter raindrops, of which $0.125,0.25,0.375,0.5 \mathrm{~mm}$ diameter of the raindrops mainly concentrated in $0.8-3.4,0.4-3.4,0.8$ $1.4,1-3.4 \mathrm{~m} / \mathrm{s}$.

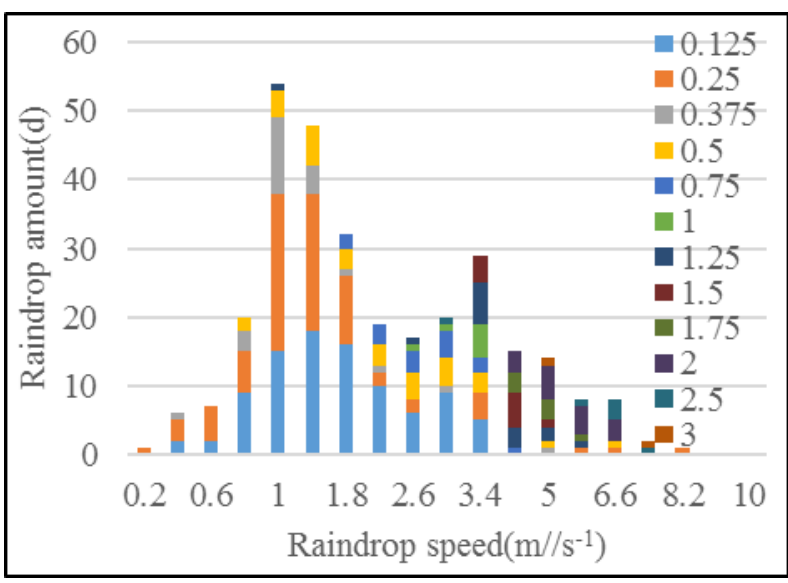

Fig.7 the fifth minute during the natural rainfall on 20160423

\section{Conclusions}

Through the analysis of natural raindrops, the following aspects were obtained:

(1) The natural rainfall process is a process of rainfall intensity changes.

(2) During the process of this rainfall, the final velocity of the rain is mainly concentrated between 0.8 $5 \mathrm{~m} / \mathrm{s}$, the peak of the final velocity is generally $1 \mathrm{~m} / \mathrm{s}$; rainfall is mainly composed of the particle size of 0.125 $0.5 \mathrm{~mm}$ raindrops. The velocity of the raindrops of $0.125 \mathrm{~mm}$ diameter is mainly between $0.8-3.4 \mathrm{~m} / \mathrm{s}$, the final velocity of the raindrops of $0.25 \mathrm{~mm}$ particle size is mainly concentrated between $0.6-3.4 \mathrm{~m} / \mathrm{s}, \quad 0.375 \mathrm{~mm}$ concentrated in the $0.8-1 \mathrm{~m} / \mathrm{s}$, the $0.5 \mathrm{~mm}$ particle size of the raindrops mainly concentrated in the $1-1.4 \mathrm{~m} / \mathrm{s}$.

\section{Acknowledgment}

We greatly appreciate our group for useful discussions on this subject and all referees for their assistance and laboratory work. This research mainly supported by Key Laboratory of Soil and Water Loss Process and Control on the Loess Plateau of the MWR Foundation (2017005) ; National Key R\&D Program of China (2017YFC0504503), National Key Technology R\&D Program (2013BAC05B04) ; the National Key Basic Research Project(2011CB403303), ISTTCP of Henan Province (162101510004)

\section{References}

1. Tang K L 2004, Soil and water conservation in China [M]. Beijing: Science Press, 2004.

2. Chen L 2002, Soil and water conservation in China [J], 2002 (7): 4-6.

3. Li Z B 1991, Storm erosion test and small watershed sediment yield model of sloping land system in Loess Region [D], Doctoral Dissertation of Shaanxi Institute of Mechanical Engineering, 1991.

4. Moldenhauer W C 1965. Procedure for studying soil characteristics using disturbed samples and 
simulated rainfall [J]. Transactions, American Society of Agricultural Engineer, 1965, 8(1):30-35.

5. Renard K G, Foster G R, Weesies G A, 1997. Predicting soil erosion by water: a guide to conservation planning with the Revised Universal Soil Loss Equation (RUSLE)[J]. Agriculture Handbook, 1997.

6. Foster G R and Lane L J 1987. User requirements, USDA-Water Erosion Prediction Project (WEPP) [R], NSERLReportNo1, West Lafayette: USDAARS National Soil Erosion Research Laboratory, 1987.

7. Nearing M A, Foster G R, Lane L J, 1989. A process-based soil erosion model for USDA-Water Erosion Prediction Project technology [J]. Trans. ASAE, 1989, 32(5): 1587-1593.

8. Laflen J M, Lwonard J L, Foster G R 1991. WEPP a new generation of erosion prediction technology[J]. J of Soil and Water Cons., 1991, 46(1): 34-38.

9. Yao W Y, Several design theories and applications of the Yellow River river channel physical simulation [D], Doctoral Dissertation of Hohai University, 2005.

10. Yao W Y, 2011, Review and Prospect of mathematical models for erosion and sediment yield in China [J]. Sediment Research, 2011, (2): 65-74.

11. Shen Z Z, Liu P L, Xie Y S 2007. Transformation of erosion types on loess slope by REE tracking [J], Journal of Rare Earths, 2007, 25 (4): 67-73.

12. Shen Z Z, Yao W Y, Li Z B, Li M, Xiao P Q, WU Y 2014. Transformation of Rainfall Characters on Soil Erosion Similar [J], Journal of Rare Earths, 2014, 32 (S): 130-133.

13. SHEN Z Z,YAO W Y, L I M,2008. Study on Correlativity Between Erosion and Seeping Under Different Underlying Horizon[J], Journal of Soil and Water Conservation, 2008, 22 (5): 43-46.

14. [1SHEN Z Z, YAO W Y, LI M, 2008. Runoff Sediment-Carrying Capacity and Critical Shear Force on Slope [J]. Journal of Tianjin University, 2008, 41(4):149-153.

15. Shen Z Z, Yao W Y, Li M 2009, Influence factors of runoff energy consumption and denudation amount on loess slope [J]. Science of Soil and Water Conservation, 2009, 7 (6): 9-13. 